\title{
In Front of Bilateral Pseudo Tumoral Ovarian Mass: Think about Tuberculosis
}

\author{
Kechaou Ines, Cherif Eya, Boukhris Imen, Azzabi Samira, Ben Hassine Lamia \\ Department B of Internal Medicine, Charles Nicolle Hospital, Tunis, Tunisia \\ Email: kechaou.ines@topnet.tn
}

Received 14 March 2016; accepted 24 May 2016; published 27 May 2016

Copyright (C) 2016 by authors and Scientific Research Publishing Inc.

This work is licensed under the Creative Commons Attribution International License (CC BY). http://creativecommons.org/licenses/by/4.0/

c) (i) Open Access

\begin{abstract}
Ovarian and peritoneal localizations of tuberculosis are rare. They raise the problem of differential diagnosis with malignancy. In this regard, we reported the case of a 25 -year-old woman who presented with bilateral pseudo tumoral ovarian mass mimicking an advanced ovarian carcinoma with ascites. Extemporaneous examination of the peritoneum confirmed the diagnosis of tuberculosis and avoided bilateral annexectomy that could compromise the fertility of the patient.
\end{abstract}

\section{Keywords}

Ovarian Tuberculosis, Ovarian Carcinoma, CA 125, Fertility

\section{Introduction}

Genital tuberculosis is a particular location of extrapulmonary tuberculosis. The most common form is represented by chronic salpingitis. However, other locations have been reported involving the endometrium, cervix and vagina exceptionally [1]. Bilateral ovarian localization is rare. It seems useful to educate clinicians about this tuberculosis localization through this clinical case observed in our institution.

\section{Observation}

A 25-year-old woman without past medical history was admitted to our department for an alteration of the general state with a $10 \mathrm{~kg}$ weight loss lasting for 3 months in a context of fever. She also reported amenorrhea since 3 months and a gradual increase in abdominal volume. Clinical examination found a febrile patient at $38^{\circ} \mathrm{C}$. The heart and lung auscultation were normal. The abdomen was distended related to ascites. The rest of her physical examination was unremarkable.

Laboratory findings on admission revealed a normal white cell count $\left(6290 / \mathrm{mm}^{3}\right)$. The erythrocyte sedimentation rate was elevated $(75 \mathrm{~mm})$. The $\mathrm{C}$ reactive protein was high $(88.3 \mathrm{mg} / \mathrm{L})$ and also the rate of serum fibrin $(4.7$

How to cite this paper: Ines, K., Eya, C., Imen, B., Samira, A. and Lamia, B.H. (2016) In Front of Bilateral Pseudo Tumoral Ovarian Mass: Think about Tuberculosis. Open Journal of Internal Medicine, 6, 27-30.

http://dx.doi.org/10.4236/ojim.2016.62006 
$\mathrm{g} / \mathrm{L}$ ). Renal and hepatic function tests were normal. The abdominopelvic CT scan showed a cystic mass of the right ovary measuring $5 \mathrm{~cm}$ in the greater axis and solido-cystic mass in the left ovary measuring $6 \mathrm{~cm}$ in the great axis. It was a great abundance ascite with thickening and nodular on the peritoneum measuring $12 \mathrm{~mm}$ (Figure 1). Furthermore, the chest X-Ray was normal. Acido-alcoolo-resistant bacillus on the sputum and tuberculin skin testing were negatives. The antigen CA125 levels were very high: $321 \mathrm{U} / \mathrm{ml}$ (normal $<30 \mathrm{U} / \mathrm{ml}$ ). Abdominal celioscopy was performed and showed countless whitish nodules throughout the peritoneal cavity. Peritoneal biopsy was performed. The macroscopic specimen of biopsy measured $6 / 1 \mathrm{~cm}$ containing whitish nodules of 0.5 to $1 \mathrm{~cm}$.

The extemporaneous study of the peritoneum was in favor tuberculosis confirming the presence of caseo follicular tuberculosis (Figure 2). Laparoscopy has not explored the pelvic area.

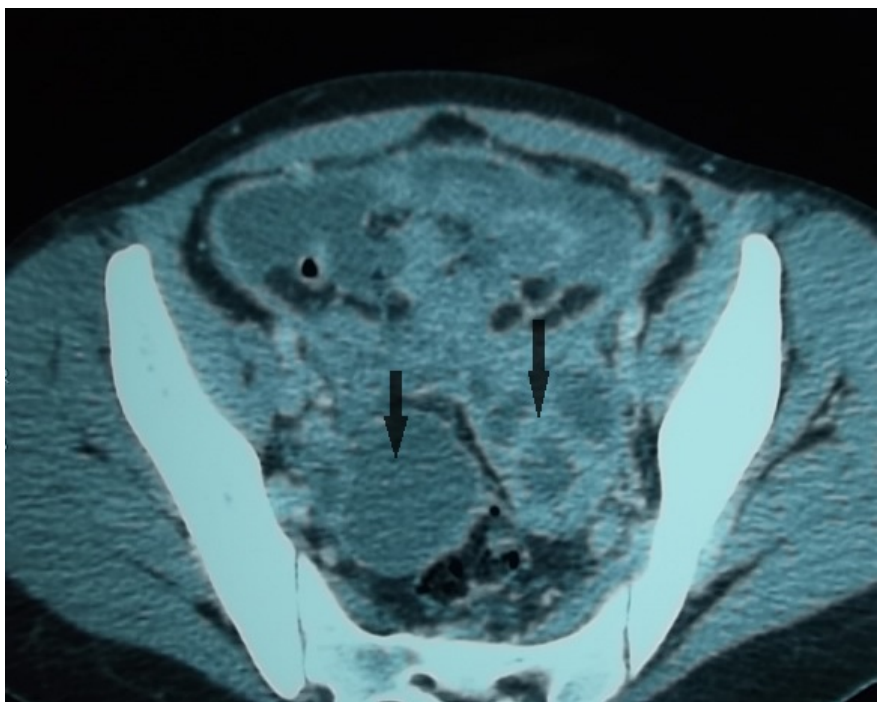

Figure 1. A cystic mass of the right ovary and solido-cystic mass in the left ovary. The arrows shows the right and the left ovaries with cystic mass of the right ovary and solidocystic mass in the left ovary.

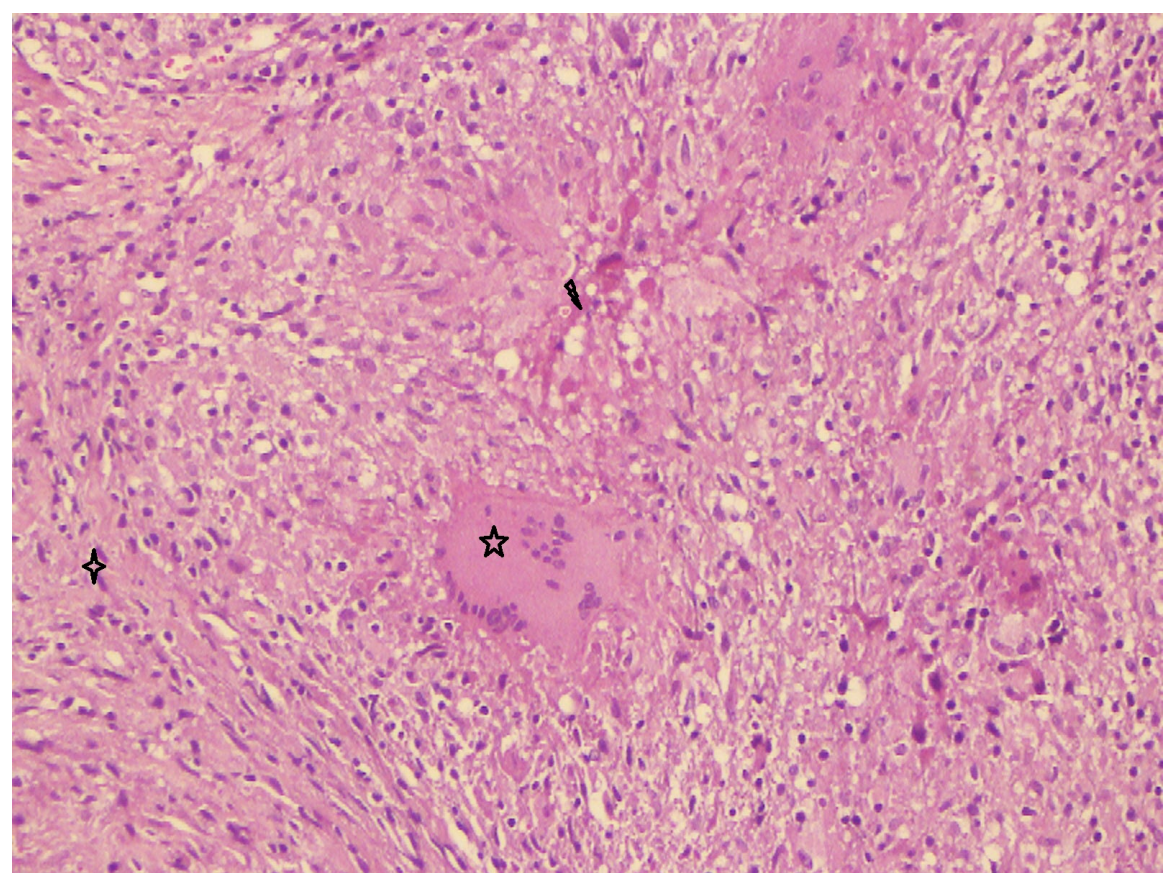

Figure 2. Epithelioid ( $\downarrow$ ) and giant ( $\downarrow$ ) cells with caseum ( $)$. 
The patient received a quadruple anti-Tuberculosis treatment: HZRE (isoniazid, pyrazinamide, rifampicin and ethambutol) protocol for 2 months and RH (isoniazid, rifampicin) for 4 months.

The evolving was good and we noted the disappearance of the ovarian mass and the resumption of menstrual cycles after 6 months of treatment. Finally the diagnosis of bifocal tuberculosis involving the ovaries and the peritoneum was retained retrospectively after improvement under treatment.

\section{Discussion}

As shown in our observation, the pseudo tumoral form of genital tuberculosis mainly affects young women between 20 and 30 years [2]. In our case, the spread of TB to the peritoneum has probably made by contiguity from the ovarian lesions.

The literature review of similar cases showed as in our case, the difficulty to differentiate between ovarian tuberculosis and advanced ovarian cancer, based on clinical, biological and imaging findings before surgical investigation [3]-[8].

Pelvic MRI is the best way to further characterize an ovarian mass. However, the distinction between neoplastic and tuberculosis remains difficult [3].

The elevation of CA 125 levels is usually observed in $90 \%$ of advanced ovarian cancer. However, this rise remains non-specific as it can be observed in various circumstances such as pregnancy, ovarian cysts, uterine cancer, colon, lung and pancreatic cancer ... [9]. The association of tuberculosis and high levels of CA125 has been reported in the literature, and its decrease might be a good marker for an appropriate response after anti-tuberculosis treatment [2] [10].

Pathological examination is the best way to confirm the right diagnosis. However, this option is not without drawbacks because of the risk of infertility that could follow bilateral oophorectomy [11]. In our young patient, extemporaneous examination of the peritoneum avoided the realization of a more invasive procedure in order to conserve her fertility. Indeed, this diagnosis was made retrospectively and the patient preserved her ovaries.

The duration of treatment of the genital tract tuberculosis is the same as pulmonary tuberculosis, for 6 months $[12]$.

\section{Conclusions}

Peritoneal and ovarian tuberculosis can clinically and radiologically simulate malignancy. But, in front of pseudo-tumoral ovarian mass in a young woman, we must think about tuberculosis.

Considering the curability of this serious infectious disease, it would be interesting to use more accessible bacteriological samples in order to avoid more invasive procedures.

\section{Conflict of Interest}

None.

\section{References}

[1] Fillion, A., Koutlidis, N., Froissart, A. and Fantin, B. (2014) Investigation and Management of Genito-Urinary Tuberculosis. La Revue de Médecine Interne, 35, 808-814. http://dx.doi.org/10.1016/j.revmed.2014.07.006

[2] Liu, Q., Zhang, Q., Guan, Q., Xu, J.F. and Shi, Q.L. (2014) Abdominopelvic Tuberculosis Mimicking Advanced Ovarian Cancer and Pelvic Inflammatory Disease: A Series of 28 Female Cases. Archives of Gynecology and Obstetrics, 289, 623-629. http://dx.doi.org/10.1007/s00404-013-3034-2

[3] Fakhrolmolouk, Y. and Farah, F. (2009) Familial Tuberculosis Mimicking Advanced Ovarian Cancer. Infectious Diseases in Obstetrics and Gynecology, 2009, Article ID: 736018.

[4] Mahdavi, A., Malviya, V.K. and Herschman, B.R. (2002) Peritoneal Tuberculosis Disguised as Ovarian Cancer: An Emerging Clinical Challenge. Gynecologic Oncology, 84, 167-170. http://dx.doi.org/10.1006/gyno.2001.6479

[5] Lantheaume, S., Soler, S., Issartel, B., et al. (2003) Peritoneal Tuberculosis Simulating Advanced Ovarian Carcinoma: A Case Report. Gynécologie Obstétrique \& Fertilité, 31, 624-626. http://dx.doi.org/10.1016/S1297-9589(03)00179-6

[6] Bilgin, T., Karabay, A., Dolar, E. and Develioglu, O.H. (2001) Peritoneal Tuberculosis with Pelvic Abdominal Mass, Ascites and Elevated CA 125 Mimicking Advanced Ovarian Carcinoma: A Series of 10 Cases. International Journal of Gynecological Cancer, 11, 290-294. http://dx.doi.org/10.1046/j.1525-1438.2001.011004290.x 
[7] Gurbuz, A., Karateke, A., Kabaca, C., Kir, G. and Cetingoz, E. (2006) Peritoneal Tuberculosis Simulating Advanced Ovarian Carcinoma: Is Clinical Impression Sufficient to Administer Neoadjuvant Chemotherapy for Advanced Ovarian Cancer? International Journal of Gynecological Cancer, 16, 307-312. http://dx.doi.org/10.1111/j.1525-1438.2006.00209.x

[8] Yazdani, S., Sadeghi, M., Alijanpour, A. and Naeimirad, M. (2016) A Case Report of Peritoneal Tuberculosis with Multiple Military Peritoneal Deposits Mimicking Advanced Ovarian Carcinoma. Caspian Journal of Internal Medicine, 7, 61-63.

[9] Cragun, J.M. (2011) Screening for Ovarian Cancer. Cancer Control, 18, 16-21.

[10] Rabesalama, S.S.E.N., Mandeville, K.L., Raherison, R.A. and Rakoto-Ratsimba, H.N. (2011) Isolated Ovarian Tuberculosis Mimicking Ovarian Carcinoma: Case Report and Literature Review. Southern African Journal of Infectious Diseases, 5, 7-10. http://dx.doi.org/10.4314/ajid.v5i1.66508

[11] Nezar, M., Goda, H., El-Negery, M., El-Saied, M., Wahab, A.A. and Badawy, A.M. (2009) Genital Tract Tuberculosis among Infertile Women: An Old Problem Revisited. Archives of Gynecology and Obstetrics, 280, 787-791. http://dx.doi.org/10.1007/s00404-009-1000-9

[12] Filliona, A., Koutlidisb, N., Froissartc, A. and Fantin, B. (2014) Investigation and Management of Genito-Urinary Tuberculosis. La Revue de Médecine Interne, 35, 808-814. 